\title{
Update on HCDstruct - A Tool for Hybrid Wing Body Conceptual Design and Structural Optimization
}

\author{
Frank H. Gern ${ }^{1}$ \\ NASA Langley Research Center, Hampton, VA 23681
}

\begin{abstract}
HCDstruct is a Matlab ${ }^{\circledR}$ based software tool to rapidly build a finite element model for structural optimization of hybrid wing body (HWB) aircraft at the conceptual design level. The tool uses outputs from a Flight Optimization System (FLOPS) performance analysis together with a conceptual outer mold line of the vehicle, e.g. created by Vehicle Sketch Pad (VSP), to generate a set of MSC Nastran ${ }^{\circledR}$ bulk data files. These files can readily be used to perform a structural optimization and weight estimation using Nastran's ${ }^{\circledR}$ Solution 200 multidisciplinary optimization solver. Initially developed at NASA Langley Research Center to perform increased fidelity conceptual level HWB centerbody structural analyses, HCDstruct has grown into a complete HWB structural sizing and weight estimation tool, including a fully flexible aeroelastic loads analysis. Recent upgrades to the tool include the expansion to a full wing tip-to-wing tip model for asymmetric analyses like engine out conditions and dynamic overswings, as well as a fully actuated trailing edge, featuring up to 15 independently actuated control surfaces and twin tails. Several example applications of the HCDstruct tool are presented.
\end{abstract}

\begin{tabular}{|c|c|c|c|c|c|}
\hline \multicolumn{6}{|c|}{ Nomenclature } \\
\hline ARD & $=$ & $\begin{array}{l}\text { Aeronautics Research Directorate } \\
\text { at NASA Langley }\end{array}$ & LSAF & $=$ & $\begin{array}{l}\text { Boeing's Low Speed Aeroacoustic } \\
\text { Facility }\end{array}$ \\
\hline ARMD & $=$ & Aeronautics Research and Mission & MAC & $=$ & Mean Aerodynamic Chord \\
\hline & & Directorate at NASA & MDO & $=$ & Multidisciplinary Optimization \\
\hline BWB & $=$ & Blended Wing Body & MDOPT & $=$ & Boeing's Multidisciplinary Design \\
\hline CFD & $=$ & Computational Fluid Dynamics & & & Optimization Framework \\
\hline COLTS & $=$ & $\begin{array}{l}\text { Combined Loads Test System at } \\
\text { NASA Langley }\end{array}$ & NASA & $=$ & $\begin{array}{l}\text { National Aeronautics and Space } \\
\text { Administration }\end{array}$ \\
\hline ERA & $=$ & $\begin{array}{l}\text { Environmentally Responsible } \\
\text { Aviation Project at NASA }\end{array}$ & $\begin{array}{l}\text { OML } \\
\text { OREIO }\end{array}$ & $\begin{array}{l}= \\
=\end{array}$ & $\begin{array}{l}\text { Outer Mold Line } \\
\text { Boeing Open Rotor Engine }\end{array}$ \\
\hline EDS & $=$ & $\begin{array}{l}\text { Georgia Tech's Environmental } \\
\text { Design Space }\end{array}$ & PAI & $=$ & $\begin{array}{l}\text { Integration on a BWB } \\
\text { Propulsion Airframe Integration }\end{array}$ \\
\hline FEM & $=$ & Finite Element Method & PRSEUS & $=$ & Pultruded Rod Stitched Efficient \\
\hline FLOPS & $=$ & Flight Optimization System & & & Unitized Structure \\
\hline HCDstruct & $=$ & $\begin{array}{l}\text { Hybrid wing body Conceptual } \\
\text { Design and structural analysis }\end{array}$ & SBIR & $=$ & $\begin{array}{l}\text { US Small Business Innovation } \\
\text { Research Program }\end{array}$ \\
\hline HWB & $=$ & Hybrid Wing Body & $\mathrm{T}^{3}$ & $=$ & ARMD Transformational Tools \& \\
\hline ICAO & $=$ & International Civil Aviation & & & Technologies Project \\
\hline & & Organization & TLNS & $=$ & Thin Layer Navier-Stokes \\
\hline ITD & $=$ & Integrated Technology & ULD & $=$ & Unit Load Device \\
\hline & & Demonstrator & VSP & $=$ & Vehicle Sketch Pad \\
\hline
\end{tabular}

${ }^{1}$ Senior Aerospace Engineer, Aeronautics Systems Analysis Branch, Member AIAA.

1

American Institute of Aeronautics and Astronautics 


\section{Introduction}

$\mathrm{H}$ YBRID wing body (HWB) or Blended Wing Body (BWB) aircraft concepts are considered promising alternatives to conventional tube and wing configurations due to their large potential fuel savings and increased aerodynamic efficiency. ${ }^{1}$ Fuel burn reductions of $25 \%$ and higher have been published for some ultra-high capacity configurations carrying up to 800 passengers. Most notable is the work of Liebeck and his co-workers at The Boeing Company. Their 450 passenger BWB-4501L design recently resulted in the $8.5 \%$ scale X-48B flight demonstrator (Fig. 1). ${ }^{2}$

A significant difficulty in dealing with HWB design optimization has always been the lack of a data base of known "flying" designs which may serve as calibration and validation points for conceptual design and optimization programs like NASA's Flight Optimization System (FLOPS), especially when compared to the vast amount of available tube and wing aircraft data. When transitioning from the conceptual to the preliminary design phase, the aircraft designer needs to be sure that the design chosen for further optimization is actually a viable design, and as a result of the lack of validation cases, the development of improved fidelity analysis tools becomes imperative for the conceptual design loop.

To validate the projected fuel burn and noise reduction potential of HWB designs for NASA's

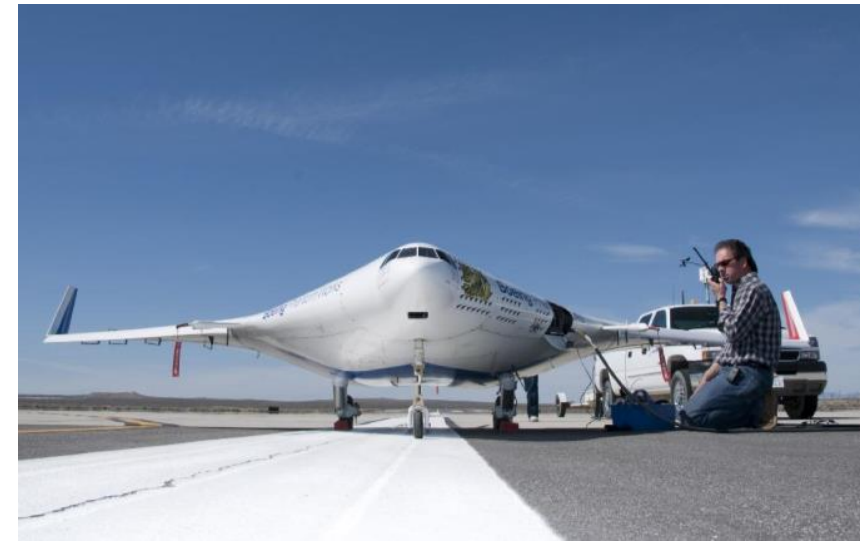

Figure 1: Boeing's X-48B Blended Wing Body flight demonstrator (NASA Photo).

Environmentally Responsible Aviation (ERA) project, significant efforts have been put forward to develop advanced structural and aerodynamic analysis tools for HWB conceptual design optimization. Aerodynamic methods improvement has been geared towards increased fidelity in-the-loop methods like enhanced panel codes and computational fluid dynamics (CFD). ${ }^{4}$ Recently developed structures tools include finite element model (FEM) based analyses to provide enhanced capabilities for HWB centerbody sizing and weight estimation which recently led to the approval for public release of the new HCDstruct tool (Hybrid wing body Conceptual Design and structural analysis). ${ }^{5}$

\section{HCDstruct Overview}

HCDstruct is a finite element based analysis code that closes an analysis gap between lower order conceptual design analyses and higher order, generally finite element based preliminary design type structural analysis and optimization packages. Originally, HCDstruct was developed out of the need to improve the versatility and accuracy of hybrid wing body (HWB) centerbody structural analyses for weight predictions and vehicle performance analyses in FLOPS. The FLOPS software is a multidisciplinary system of computer programs for conceptual and preliminary design and evaluation of advanced aircraft concepts. The modular nature of FLOPS allows the user to incorporate new equations and data tables that enable the program to analyze a wide variety of concepts. FLOPS is widely used at NASA for evaluating a variety of HWB and other innovative aircraft configurations.

The current FLOPS implementation for HWB centerbody sizing has been described in detail in Refs. 5 and 6. It assumes that the cabin is shaped like a "home plate" in baseball, with the point at the nose of the aircraft. This homeplate-shaped cabin is sized by assigning an area to each passenger (by using standard packing rules for the number abreast, seat pitch, and passenger class) and allowing for the required number of utility areas (i.e., lavatories, galleys, and closets) based on the number of passengers in each class. The current implementation is based on regressions from single point FEM analyses, and therefore sensitivities at off-design conditions are unknown. ${ }^{6,7}$ To increase the versatility and geometric accuracy of HWB centerbody weight predictions, it was decided early on to use the finite element modeling approach rather than the previously incorporated response surface representations. As can be seen from Figure 2, HCDstruct fills an important analysis gap between regression based implementations and more detailed preliminary design level finite element models (see e.g. Ref. 8).

HCDstruct was set up to use geometric and weights data generated by a FLOPS vehicle performance analysis. In addition, a representation of the vehicle outer mold line (OML) is required to develop a realistic layout of the primary structural configuration of the vehicle. Currently, HCDstruct interfaces with the OML output generated by Vehicle 

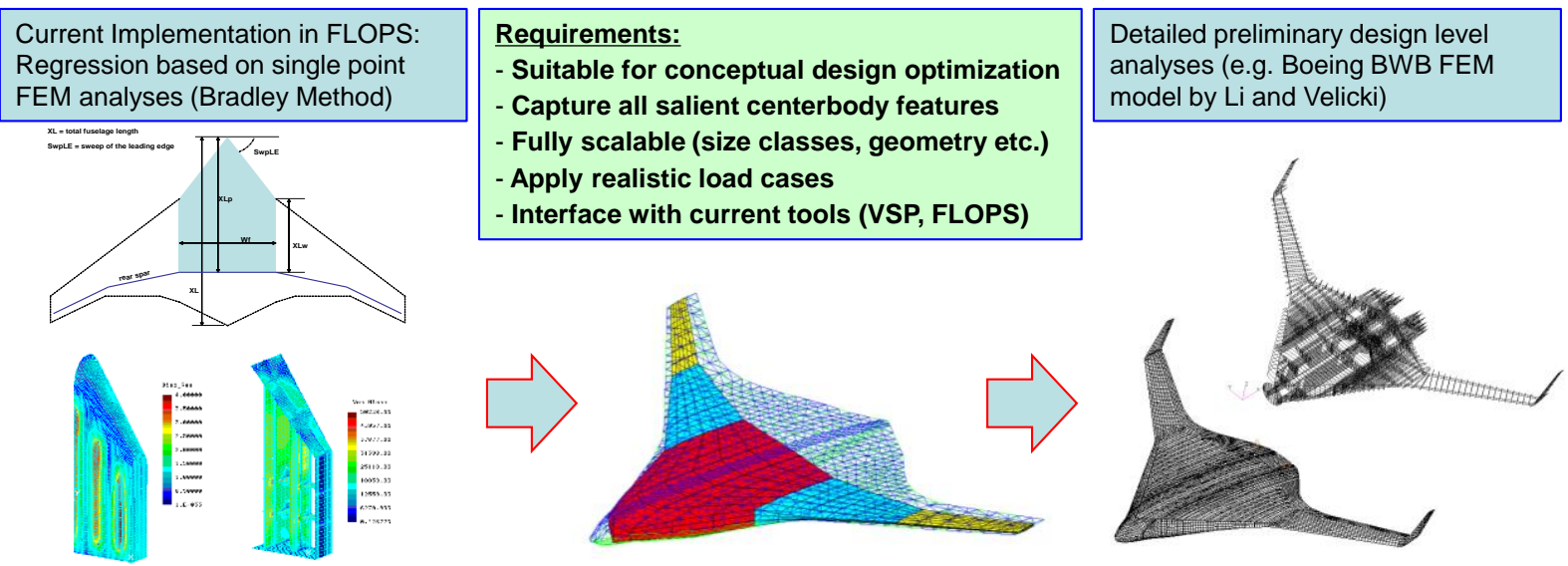

Figure 2: HCDstruct fills a critical analysis gap for conceptual HWB structural sizing between the current FLOPS implementation (Bradley Method) ${ }^{6,7}$ and more detailed preliminary design level models. ${ }^{8}$

Sketch Pad (VSP) ${ }^{9}$ for this purpose, however, only minor code modifications would be necessary to render HCDstruct compatible with any given OML representation.

HCDstruct is written as a Matlab script that reads in user-provided data, containing the above-mentioned FLOPS data and VSP OML to generate a set of MSC Nastran ${ }^{\circledR}$ bulk data files. These files contain the complete analysis deck, including load cases, structural and aeroelastic models, and Nastran's ${ }^{\circledR}$ Solution 200 multidisciplinary analysis deck for structural optimization and weight prediction.

The set of bulk data files created by HCDstruct can be readily analyzed by running MSC Nastran ${ }^{\circledR 10}$ without any additional required user modifications. In other words, although an extensive knowledge of MSC Nastran ${ }^{\circledR}$ might be helpful to run and understand the results, it is not necessarily required. The basic process flow of HCDstruct is outlined in Figure 3.

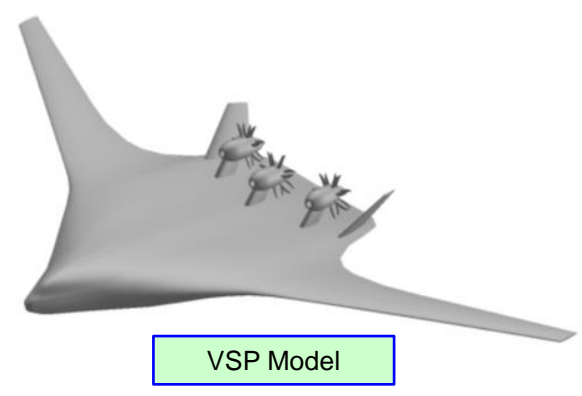

\section{Process features:}

- Suitable for conceptual design optimization

- Fully scalable (size classes, geometry etc.)

- Application of realistic load cases

- Interfaces with current tools (VSP, FLOPS)

- Captures all salient structural features (spars, skins, internal and external walls etc.)

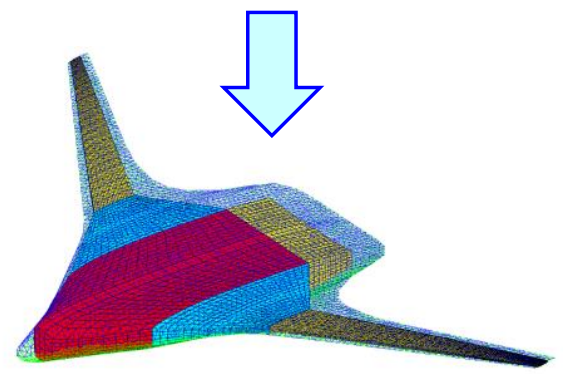

Primary structure extracted from VSP OML

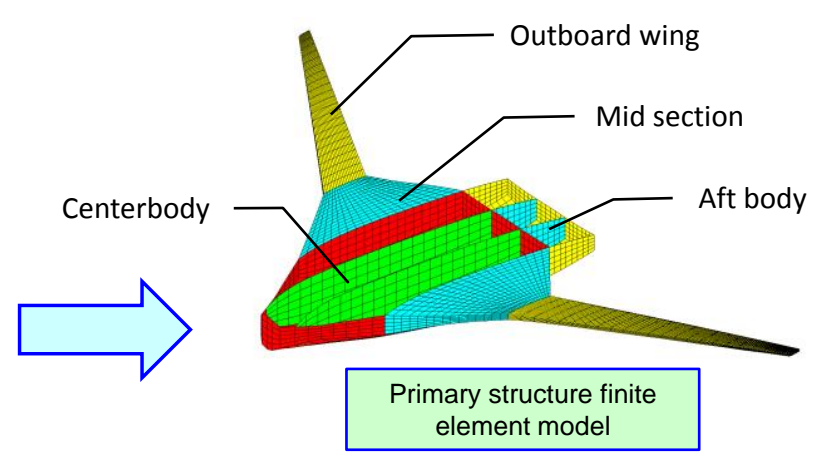

Figure 3: HCDstruct Process flow. 


\section{Reference Case - The Boeing OREIO}

In October 2010, the Aeronautics Systems Analysis Branch at NASA Langley asked Boeing Research and Technology in Huntington Beach, CA to perform a systems analysis of an HWB open rotor concept at the conceptual design level. ${ }^{11}$ Together with test data from a recent acoustics test at Boeing's Low Speed Aeroacoustic Facility (LSAF) ${ }^{12}$ this concept has been used by NASA to estimate the overall noise and fuel burn performance of an open rotor HWB. In accordance with NASA's Environmentally Responsible Aviation (ERA) project goals, the configuration was intended for entry into service by 2025 . The ERA project has a goal of simultaneously reducing noise (42db cumulative below the Stage 4 certification level), fuel burn (50\% reduction compared to currently operating aircraft), and emissions ( $75 \%$ reduction in nitrogen oxide compared to the current standard). ${ }^{13}$

The study also investigated the problem of propulsion airframe integration (PAI) due to the installation of an open rotor configuration on an HWB. At Boeing, the design was commonly referred to as OREIO, standing for Open Rotor Engine Integration on an HWB. Due to the non-proprietary nature of its performance and design data, the OREIO has developed into an important reference case and is also included as an example test case in the HCDstruct program package.

Performance requirements for the OREIO are based on the NASA ERA requirements stated above, with the primary exception that the cruise Mach number is reduced from 0.85 to 0.80 to better accommodate open rotor propulsion. For the OREIO study, NASA specified an HWB freighter configuration with a 100,000lb payload capacity, including the Unit Load Device (ULD) tare weight. Wingspan is constrained to the $65 \mathrm{~m}(213.25 \mathrm{ft}$ ) limit for International Civil Aviation Organization (ICAO) Code E airports, ${ }^{14}$ a reasonable limit for this capacity HWB that, unconstrained, optimizes near this span. Wing folding is not considered in the interest of simplicity, although it may be entertained in future studies if the $65 \mathrm{~m}$ limit proves to be a significant constraint. The objective function for design optimization is fuel consumption.

The optimization at Boeing was performed using the Multidisciplinary Design Optimization (MDOPT) framework, an aerodynamic and multidisciplinary constrained optimization that is based on a design of experiments. ${ }^{15}$ The CFD code that was coupled to the optimizer for this work was TLNS (Thin Layer Navier-Stokes). Only the wing and body were modeled for ease of gridding and speed of computation. The optimization constrained the center of pressure between 39\% and 40\% mean aerodynamic chord (MAC). Thrust effects were accounted for by assuming that thrust equals drag and that the moment arm for the thrust vector was 180 " above the center of gravity. The optimization was performed at a lift coefficient of 0.25 and an altitude of 35,000ft. After the MDOPT optimization was complete, the pressure distribution was smoothed using CDISC, a CFD based inverse design tool coupled with CFL3D as a flow solver. ${ }^{16}$ The final OREIO geometry was then smoothed manually and is shown in Figure $4 .{ }^{11}$

In their NASA contractor report, Boeing published a detailed weight breakdown for the OREIO. This weight breakdown will serve as a baseline for the present modeling studies and is given in Ref. 11.

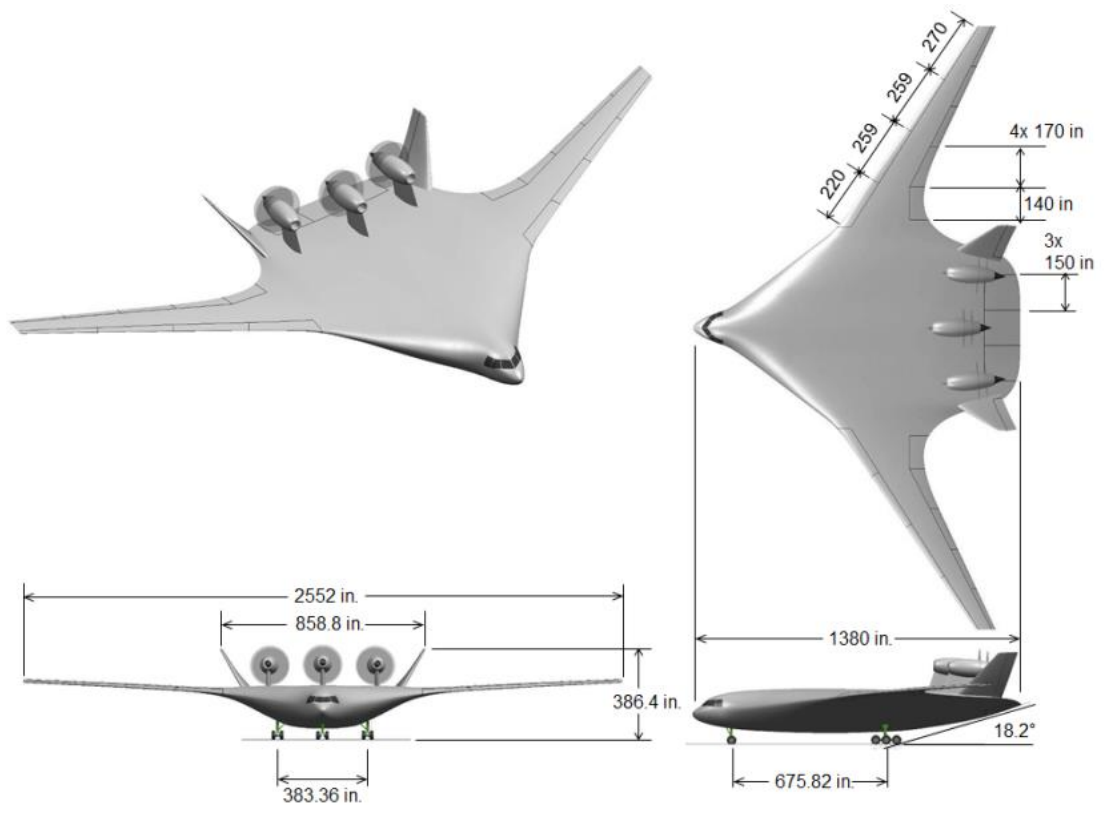

Figure 4: Three-view rendering of Boeing's optimized OREIO HWB. ${ }^{11}$ 


\section{OREIO Conceptual Design Finite Element Model Using HCDstruct}

Boeing performed a detailed aerodynamic performance optimization and analyzed a wide variety of propulsion airframe integration issues associated with open rotor installation on an HWB concept. Since a detailed structural analysis was out of the scope of this effort, HCDstruct was used to develop a suitable finite element model of the OREIO for structural design optimization and weight estimation.

\section{A. VSP Outer Mold Line Data and Centerbody Parameterization}

To ensure compatibility with previous structural modules implemented in FLOPS, the "home plate" geometry introduced by Nickol and McCullers has been used to define the main parameters of the centerbody finite element model (see Refs. 3 and 6). The centerbody "home plate" geometry is projected onto the HWB OML (Figure 5) and the centerbody geometry is then created by slicing the OML surface data at the home plate boundaries. Details regarding this procedure can be found in Ref. 5.

The complete OREIO primary structure is represented by four components: centerbody, mid section, outboard wing, and aft body (see Figure 3). The mid section, outboard wing, and aft body of the HWB are added to the structural model to allow for proper application of wing lift and moment distributions on the centerbody. The chordwise locations of front and rear spars for both mid section and outboard wing are assumed to be at $12.5 \%$ and $62.5 \%$, respectively. However, due to the parametric nature of the structural representation, these parameters can easily be modified to explore other design options. The front bulk head of the centerbody is defined by standard cockpit size assumptions. The aft body section is considered non-pressurized and generally carries the engine loads as well as vertical tails, if present. To highlight the resulting HWB structural representation, Figure 3 also shows the OREIO primary structure overlaid to the OML obtained from the VSP model as well as the resulting structural components for FEM modeling.

All structural components are modeled as CQUAD4 finite elements in Nastran ${ }^{\circledR} .{ }^{10}$ The complete design model for the finite element analysis and optimization features front spars, rear spars, skin sections, side walls, and internal walls if applicable.

Three different centerbody design options are available in HCDstruct, a single bay, a three-bay, or a five-bay design. The model utilizing the basic single bay centerbody design does not feature any internal walls and generally highly overpredicts centerbody weights. As shown in Ref. 17 a three-bay centerbody design is the option most representative of the OREIO structural layout.

\section{B. Stiffened Panel Modeling}

Researchers at The Boeing Company in Huntington Beach, California have been developing highly-integrated stitched-composite airframe structures tailored and optimized to exploit the orthotropic nature and processing advantages of carbon fiber materials. The Pultruded Rod Stitched Efficient Unitized Structure (PRSEUS) ${ }^{18}$ concept departs from conventional laminated composite design practices, manufacturing processes, and tooling techniques. This leads to substantial reductions in manufacturing and assembly costs while yielding the higher levels of structural performance that are critical for HWB airframes. ${ }^{19}$ The PRSEUS approach is deemed necessary for the HWB because of its potential to enable the flat-sided pressure cabin to be weight-competitive with traditional circular fuselage shells.

Modeling stiffened panels, and even more so the PRSEUS structural concept, in a conceptual design environment presents significant challenges in terms of FEM model size and complexity. However, in order to realistically apply displacement constraints for design optimization, the overall stiffness of the structural components must be matched. For this purpose, the 12I/T**3 entry in the Nastran PSHELL card has been modified from its default value of 1 to a value reflecting the actual bending moment of inertia of the PRSEUS panels vs. the bending stiffness of a homogenous shell. ${ }^{10}$ 


\section{Nastran Design Optimization Model}

For structural analysis and optimization of the OREIO, HCDstruct was used to develop a fully aeroelastic finite element model in MSC Nastran ${ }^{\circledR}$. Details of the baseline structural and aerodynamic modeling can be found in Refs. 5 and 17. Systems weights, payload, and fuel weight distributions are added to the structural model to account for inertia effects. Concentrated masses represent landing gears and open rotor engines, and are also distributed along the elastic axis of the vertical tail. Proper application of all nonstructural weights to the aeroelastic model will allow for using Nastran's TRIM ${ }^{10}$ solution to individually trim the airplane for each maneuver load case during the optimization, leading to more realistic results and structural weight predictions (Figure 6).

To apply aerodynamic loads, HCDstruct slices the original VSP OML at given spanwise locations to obtain planform geometries for the Nastran CAERO doublet lattice panels. Wing twist and camber distributions are extracted from VSP airfoil data and applied to the aerodynamic panels as a fixed downwash. Aerodynamic loads are splined onto the front and rear spars to accurately apply forces and moments to the structure. Details regarding the aeroelastic modeling can be found in Ref. 17.

Nastran's Solution 200 (SOL200) is used for structural analysis and design optimization. ${ }^{20}$ In SOL200, the design optimization is multi-disciplinary in the sense that the optimization for all load cases is performed simultaneously. The total structural weight was used as an objective function to be minimized. Design variables include the individual panel thicknesses of the centerbody, mid section, outboard wing, and aft section elements. Thickness constraints are placed on the design variables to account for minimum gauge limitations. Stress constraints are based on PRSEUS material properties. Displacement constraints for the centerbody under the 1.33P pressure condition (see section D) are based on maximum allowable deformations to maintain aerodynamic flow quality. ${ }^{5}$

\section{Load Cases for Structural Sizing}

Loads assumptions for commercial transport aircraft are defined in FAR Part $25 .{ }^{21}$ To fully satisfy these regulations, the airframe manufacturer generally has to analyze thousands of different load cases throughout the flight envelope to identify the critical ones. Only a subset of critical load cases is used in preliminary design, with an even smaller subset of only a few load cases being used for conceptual design optimization. A comprehensive overview and load case development of design critical load cases for HWB platforms is presented in Ref. 22.

Different combinations of payload and fuel weight scenarios have been evaluated to develop worst case assumptions for each load case. As a result, the load cases used for structural sizing of the OREIO are

- $\quad 2.5$-g limit load (full payload, zero fuel)

- 2.5-g limit load (full payload, full fuel)

- $\quad$-1.0-g limit load (full payload, zero fuel)

- $\quad-1.0-\mathrm{g}$ limit load (full payload, full fuel)

- 2.0-g taxi bump (full payload, full fuel)

- $1.33 \mathrm{P}$ cabin overpressurization (centerbody only)

A safety factor of 1.5 has been applied to the limit load stress margins to account for ultimate loads. Only symmetric load conditions are currently implemented, therefore only a half-model is required for analysis and design optimization. As Figure 6 shows, a full model can easily be created from the half model by mirroring the aeroelastic model across the $\mathrm{x}$-z-plane. This will allow for the implementation of asymmetric load cases like engine out conditions

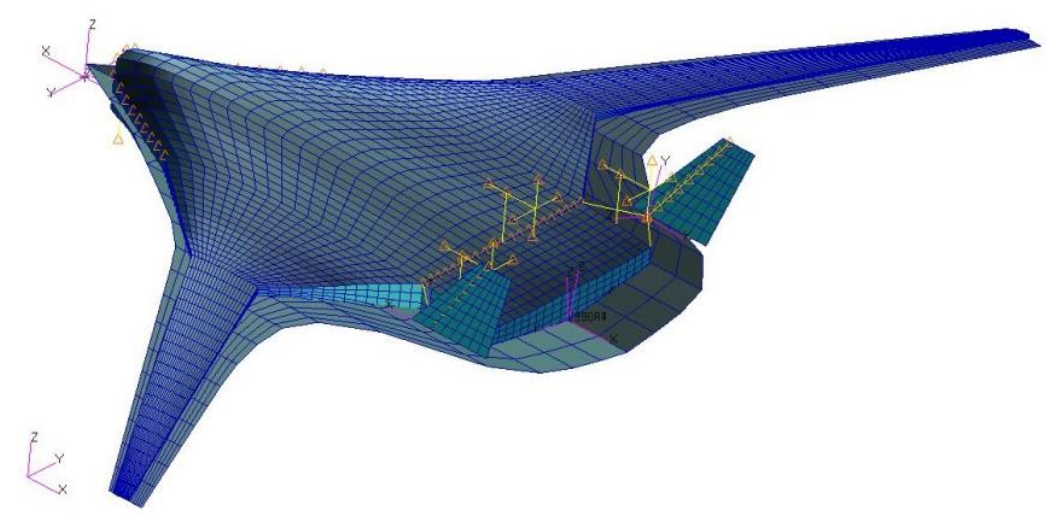

Figure 6: Nastran design model of the OREIO primary structure generated by HCDstruct. 
or dynamic overswings. Some of these cases are driven by asymmetric thrust conditions and high side loads on the vertical tails. As a result, adding these load cases would likely increase the fidelity of aft body sizing and optimization.

\section{E. Structural Optimization and Weight Calculation}

Structural weights are automatically calculated by Nastran when using weight as an objective function. To obtain the total centerbody weight, the PRSEUS material density of $0.057 \mathrm{lb} / \mathrm{in}^{3}$ is multiplied by a correction factor accounting for weight penalties due to production breaks, the centerbody leading edge, main and cargo deck floors, doors and supports, maintenance platforms, lightning protection, as well as paint, primer, and sealant. A front bulkhead simulates a closed pressure vessel for the 1.33P internal pressure load without the need to model the complex cockpit geometry, while still applying realistic loads to the centerbody front section.

The combined weight of cockpit and nose is assumed to be constant at 1,995lbs. Generally, this number does not vary significantly with aircraft size due to commonality requirements of modern aircraft family designs. Similar nonoptimum factors were applied to the wing weight calculation. For comparison purposes, non-structural wing weight factors are identical to the ones used in FLOPS. More details regarding the different wing weight terms in FLOPS and the wing weight calculation are discussed in Ref. 17.

\section{F. Nastran Structural Optimization Results}

A detailed discussion of optimization results for the OREIO primary structural weight is given in Ref. 17. However, for the sake of completeness, selected results of this analysis are recorded here. Figure 7 shows deformation results for the optimized OREIO configuration for both the 1.33P internal pressure load (a) and the 2.5-g maneuver load case (b).

Figure 8 shows a comparison of the structural weight breakdowns from three different analyses for the OREIO reference case: FEM-based (HCDstruct), Boeing, and FLOPS. No effort was made to calibrate or match numbers to

a) Optimized configuration (1.33P)

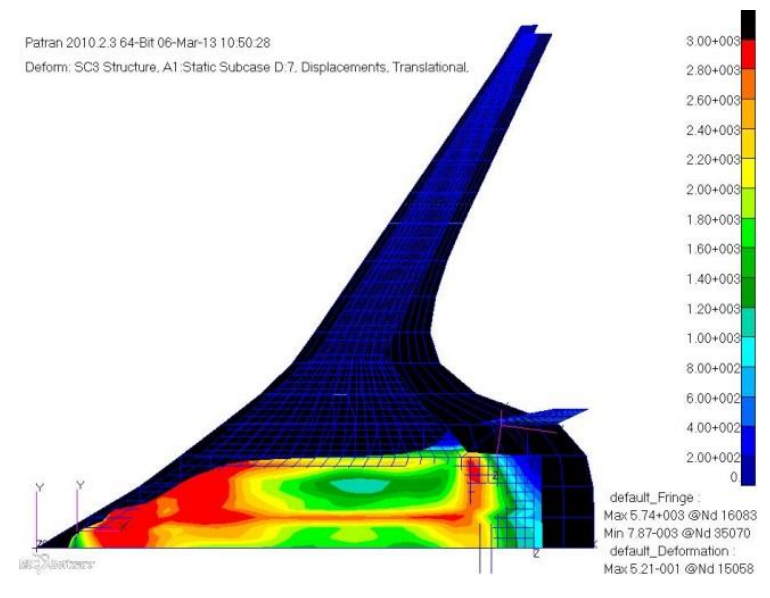

b) Optimized configuration (2.5-g)

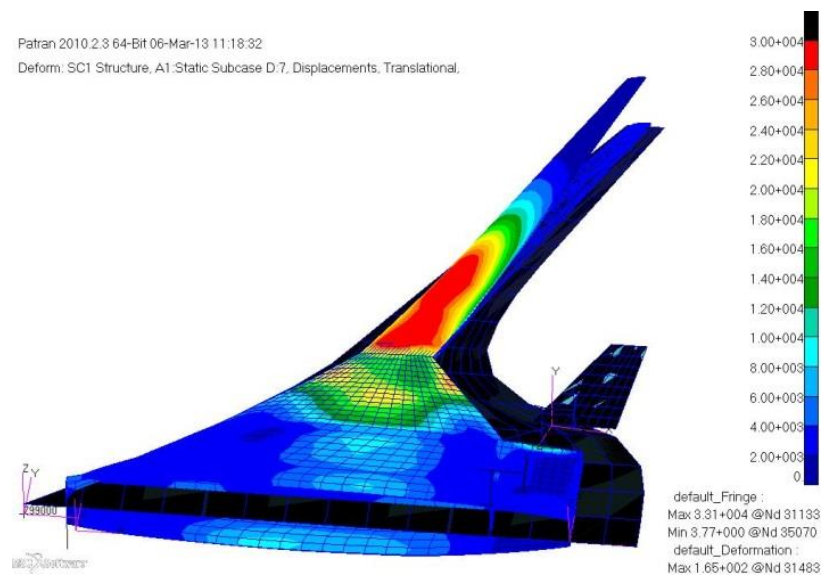

Figure 7: OREIO Optimized structural deformations and stress tensors for 1.33P cabin overpressurization and 2.5-g maneuver load (deformations not to scale).

one specific analysis, and the number of significant digits in the results is not an indicator of the accuracy or high fidelity of the analyses. However, for validation and traceability purposes, the direct analyses results are shown without truncation or rounding.

Centerbody Weight: For the FEM-based analysis, the cockpit weight is bookkept separately and therefore shown as an individual item. The combined weight of cockpit and centerbody from the FEM analysis $(52,320 \mathrm{lbs})$ is within $2 \%$ of the Boeing value $(51,600 \mathrm{lbs})$. The calibration and validation procedure for the FEM model is described in detail in Ref. 5. FLOPS predicts a significantly higher centerbody weight than both the FEM and Boeing analyses (77,412lbs). 
Wing Weight: While FLOPS predicts the lowest wing weight $(49,419 \mathrm{lbs})$, the deviation between the Boeing wing weight $(61,143 \mathrm{lbs})$ and the FEM-based wing weight $(59,412 \mathrm{lbs})$ is less than $3 \%$. For both FLOPS and FEM, the nonstructural weights terms for the wing weight are calculated using the same assumptions. ${ }^{6}$ The FLOPS methodology includes three weights terms which were combined to calculate the total wing weight:

- Term 1 is calculated from the wing bending loads,

- Term 2 represents control surfaces and shear material,

- Term 3 depends entirely on the wing area and covers miscellaneous wing items.

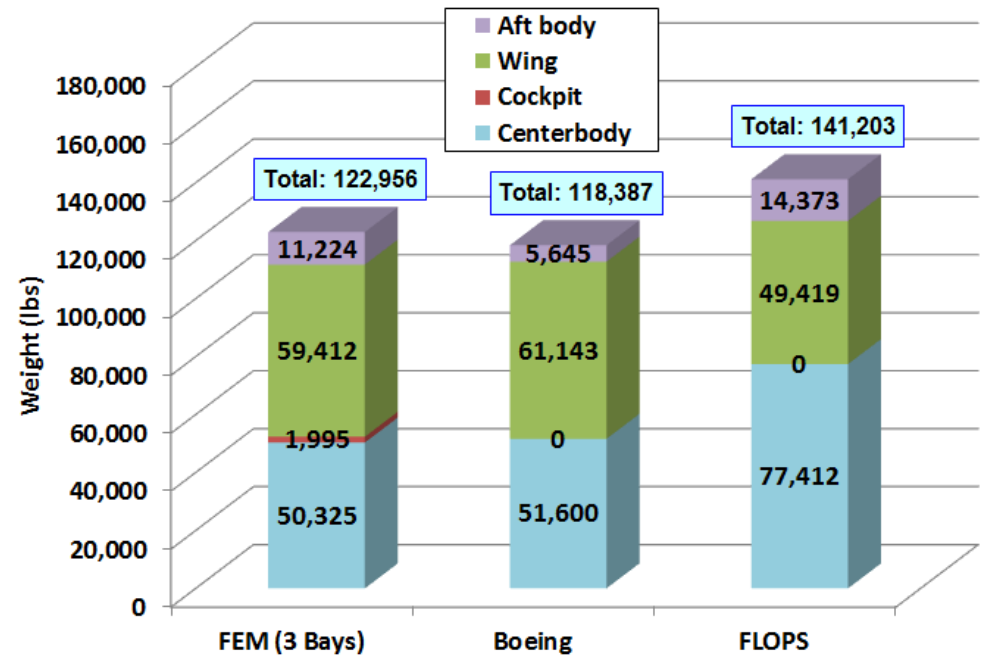

Figure 8: OREIO Weights comparison for different analyses.

Since the FEM analysis directly replaces Term 1, a multiplication factor is derived from the FLOPS analysis to calculate the total wing weight based on the ratios of Terms 1, 2, and 3 .

Another option would be to only use Term 1 from the FEM analysis and calculate the total wing weight by keeping Terms 2 and 3 from the FLOPS analysis. This would result in a significantly lower total wing weight for the FEMbased analysis $(52,936 \mathrm{lbs})$ and indicates that FLOPS tends to underestimate the structural wing weight portion for this design. Applying this procedure would also reduce the versatility of the FEM model, as the obtained weight number would only be valid for the exact same geometry; an additional FLOPS analysis would always be required to calculate the additional wing weight terms.

Aft Body Weight: For HWB analyses in FLOPS, a Term 4 is added to the wing weight breakdown to account for the weight of the aft body. The FEM based aft body weight prediction of $11,224 \mathrm{lbs}$ is about $22 \%$ lighter than the FLOPS aft body weight (14,373lbs), while the Boeing analysis only predicts 5,645lbs. These numbers show that the highest uncertainty for structural weight prediction lies in the determination of the weight of the aft body structure. The aft body weight is primarily driven by inertia and thrust loads of the engines, side loads on the vertical tails during engine out conditions, and control surface hinge moments of the large centerline trailing edge flaps. Adding more load cases like asymmetric thrust conditions and high side loads on the vertical tails are expected to reduce the uncertainty associated with aft body weight results.

Total Structural Weight: Figure 8 shows that the FLOPS analysis predicts a higher centerbody weight, while underpredicting the wing weight as compared to the two other models. Due to this compensation effect, the total structural weight from the FLOPS analysis $(141,203 \mathrm{lbs})$ still comes reasonably close to both the Boeing prediction $(118,387 \mathrm{lbs})$ and the FEM model $(122,956 \mathrm{lbs})$. The FEM model and Boeing analysis are within $4 \%$ of each other for the total structural weight.

\section{Recent HCDstruct Upgrades and Applications}

\section{A. Fully Actuated Trailing Edge and Vertical Tails}

A recent NASA Aeronautics Research and Mission Directorate (ARMD) Seedling Fund project studied the potential of applying artificial intelligence methods like neurocomputing to the control allocation optimization problem of Hybrid Wing Body (HWB) aircraft concepts. ${ }^{23}$ Researchers from NASA Langley, Virginia Tech, and Boeing Research and Technology have been exploring the use of artificial neural networks to develop innovative control algorithms minimizing control power, hinge moments, and actuator forces to keep system weights within acceptable limits. The main objective of the Phase I effort was to develop a proof-of-concept process suitable to demonstrate the potential of using neurocomputing for optimizing actuation power for aircraft featuring multiple independently actuated control surfaces. One of the key accomplishments from the Phase I project was the development of a complete proof-of-concept aeroservoelastic neurocomputing process to optimize actuation power for a representative $2.5 \mathrm{~g}$ symmetric pitch maneuver (Figure 9). 

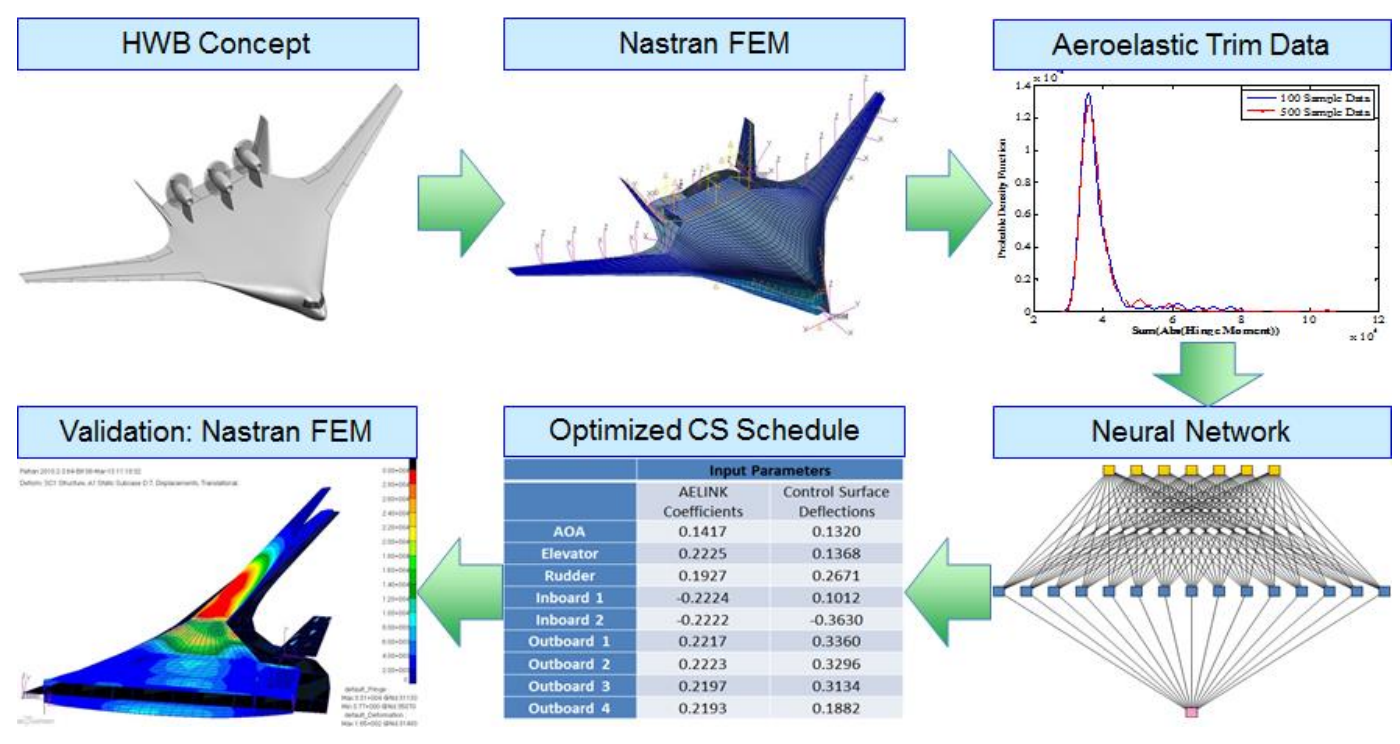

Figure 9: HCDstruct is part of a complete proof-of-concept process for aeroservoelastic neurocomputing to optimize actuation power.

HCDstruct was used to develop a full aeroelastic finite element model suitable for analyzing a representative HWB platform developed by Boeing. For this purpose, modeling capabilities were extended to include a completely actuated trailing edge, featuring 13 independent trailing edge elevons and two rudders, with the option of analyzing all-movable vertical tails as well (Figure 10). The initial analysis was investigating symmetric pitch maneuvers, therefore reducing the number of independent control surfaces to a total of seven. Due to its non-proprietary nature, the Boeing OREIO HWB concept was chosen for this task. Boeing provided control surface geometries and developed actuator dynamics models based on a Simulink analysis model that was validated through X-48 wind tunnel and flight testing. ${ }^{23}$

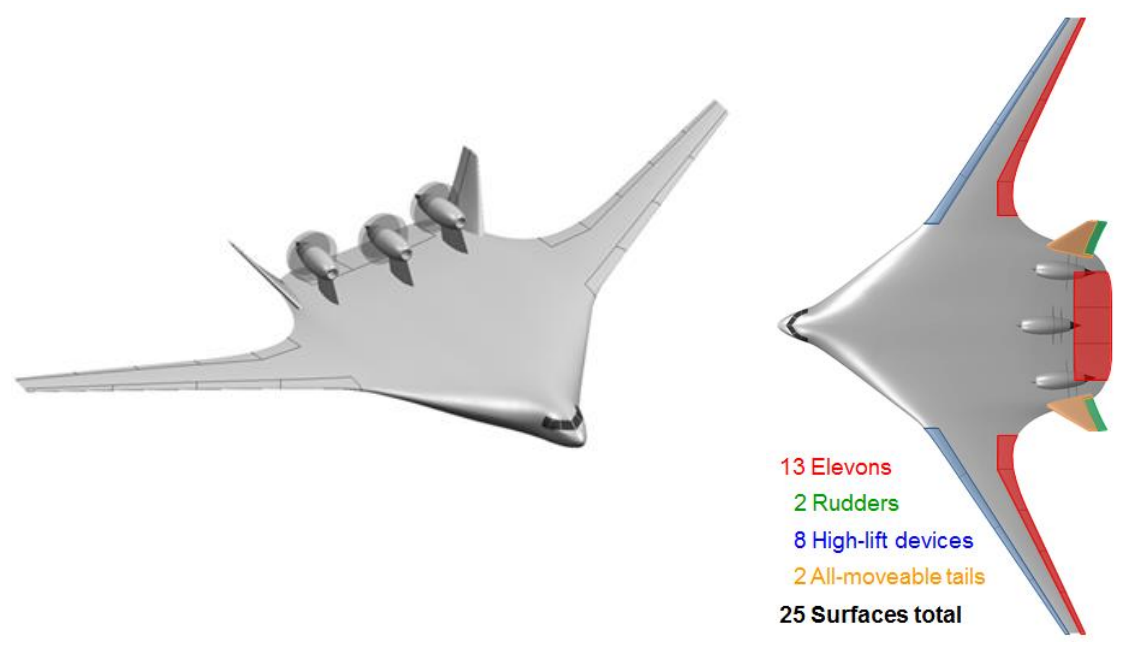

Figure 10: The Boeing OREIO HWB concept features up to 25 control surfaces and high lift devices.

The FEM model created by HCDstruct was used to generate an aeroelastic trim database containing up to 2,500 Nastran aeroelastic TRIM $^{10}$ solutions (Figure 11). For this purpose, the baseline Nastran model is used to perform a large number of maneuver-trim analyses with randomly generated linkage coefficients between the different control surfaces. Latin Hypercube Sampling is used to generate random Nastran AELINK ${ }^{10}$ card coefficients for each individual Nastran SOL144 static aeroelastic TRIM analysis. ${ }^{24}$ A Matlab script then reads trim variables, control surface deflections, and stores all this information for post-processing and optimization using artificial neural networks. Details regarding this process can be found in Ref. 23. 


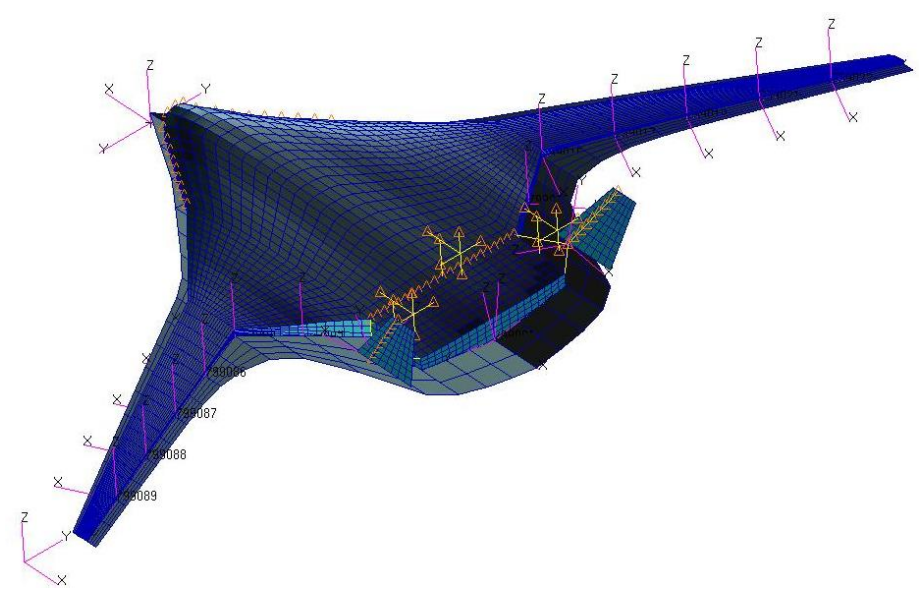

\section{Figure 11: OREIO aeroelastic finite element model generated by HCDstruct featuring a fully actuated trailing edge and vertical tail.}

Different neural network topologies and learning algorithms were investigated to train the neural network using the aeroelastic trim database. A neural network with one hidden layer of up to 300 neurons was chosen as the network to perform the actuation power optimization. The hidden layer neurons were trained using a hyperbolic tangent sigmoid transfer function, while a single output neuron featuring a linear transfer function represents the required actuation power. The neural network was optimized using a genetic algorithm to develop sets of control surface linkage coefficients minimizing the sum of all control surface hinge moments, which was the figure-of-merit used as an actuation power proxy.

The optimization results were quantified by demonstrating a more than $12 \%$ improvement over the best Nastran solution when using the neural network optimization process. ${ }^{25}$ Some of the optimization results from this work are recorded in Figure 12, an in-depth discussion of the process, modeling, and results can be found in Ref. 23. A followon project of this work is currently being funded by NASA Langley's Aeronautics Research Directorate through their Bid \& Proposal fund, as well as the NASA Aeronautics Research and Mission Directorate (ARMD) Transformational Tools \& Technologies $\left(\mathrm{T}^{3}\right)$ project under its Revolutionary Tools \& Methods sub-project.

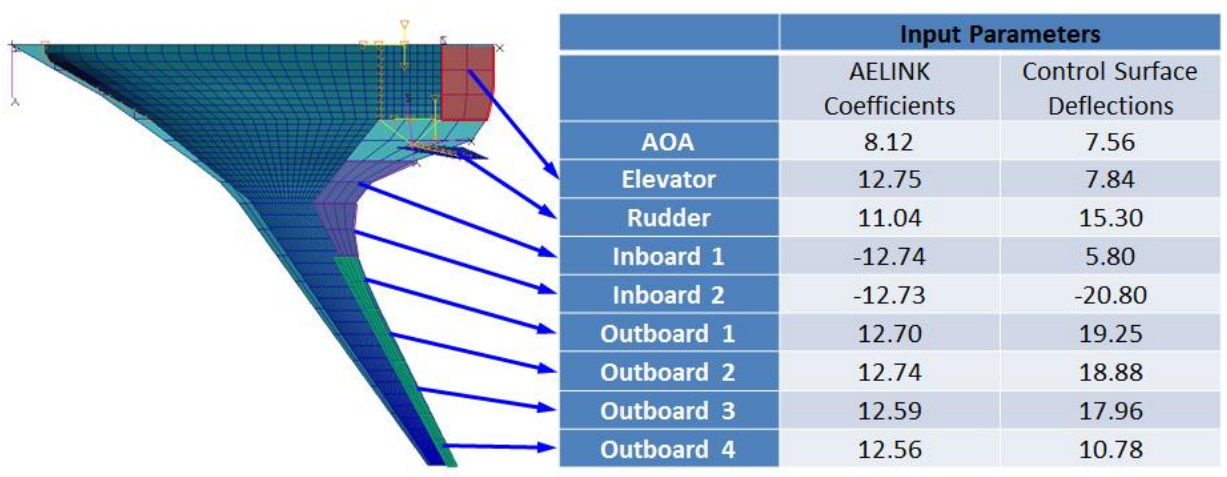

Figure 12: Optimization results for control surface deflections for a Boeing OREIO 2.5g symmetric pitch maneuver.

\section{B. HCDstruct Integration into Multidisciplinary Optimization (MDO) Environments}

Researchers at Intelligent Automation, Inc. (IAI) and Stanford University are currently developing a new process for "Variable Complexity Weight Estimation for Conceptual Aircraft Design Optimization" through a NASA Langley sponsored SBIR project. ${ }^{26}$ For this project, they developed the automated process shown in Figure 13 for importing geometries generated in OpenVSP into HCDstruct to obtain primary structural weights estimates. Current efforts at 


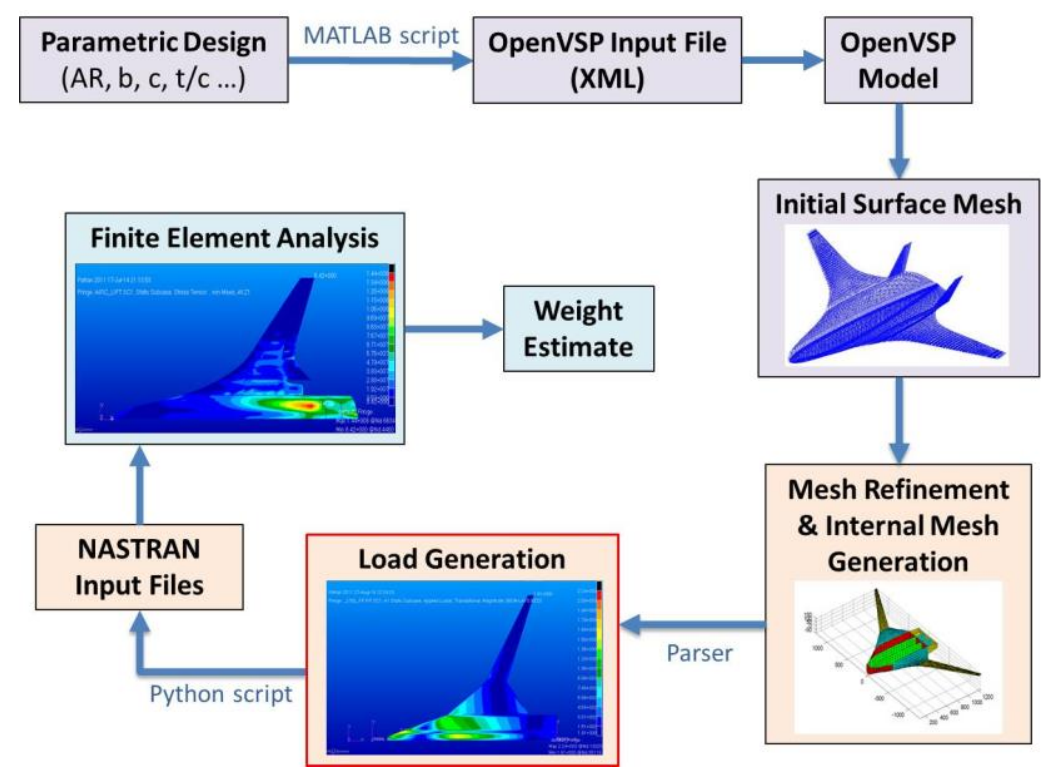

Figure 13: IAI's coupled OpenVSP/HCDstruct parametric geometry weight estimation process. ${ }^{26}$

Georgia Tech's Aerospace Systems Design Laboratory are focusing on integrating HCDstruct into their Environmental Design Space (EDS) ${ }^{27}$ aircraft modeling and simulation environment.

\section{Full Wing Tip-to-Wing Tip Model with Increased Centerbody Fidelity}

Ongoing efforts at NASA Langley include the extension of the pitch-trimmed half model for symmetric maneuver analysis and load conditions to a full wing tip-to-wing tip model incorporating antisymmetric and asymmetric analysis cases (Figure 14). This will allow for the implementation and analysis of engine out conditions or dynamic overswings. Some of these cases are driven by asymmetric thrust conditions and high side loads on the vertical tails. Adding these load cases is anticipated to increase the fidelity of aft body sizing and optimization, which in previous analyses has exhibited the highest degrees of uncertainty. ${ }^{17}$

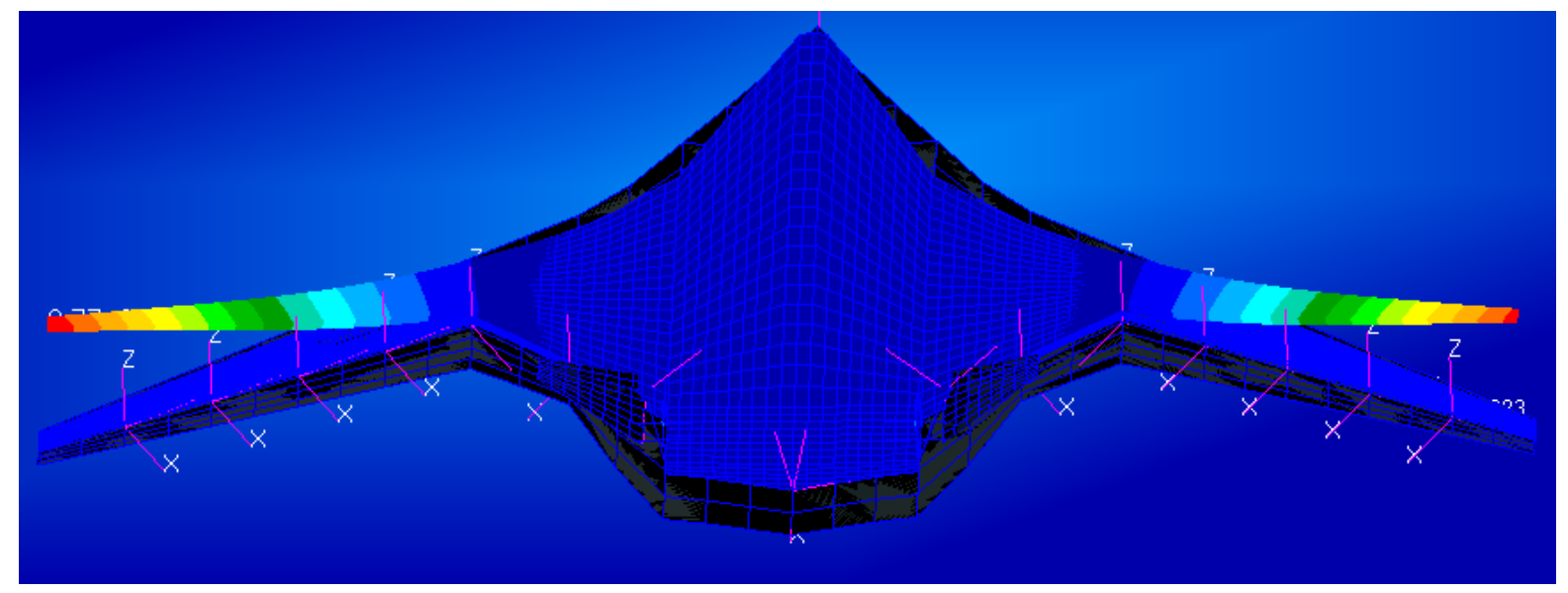

Figure 14: NASA's updated version of HCDstruct generates a full wing tip-to-wing tip model incorporating asymmetric load conditions. 


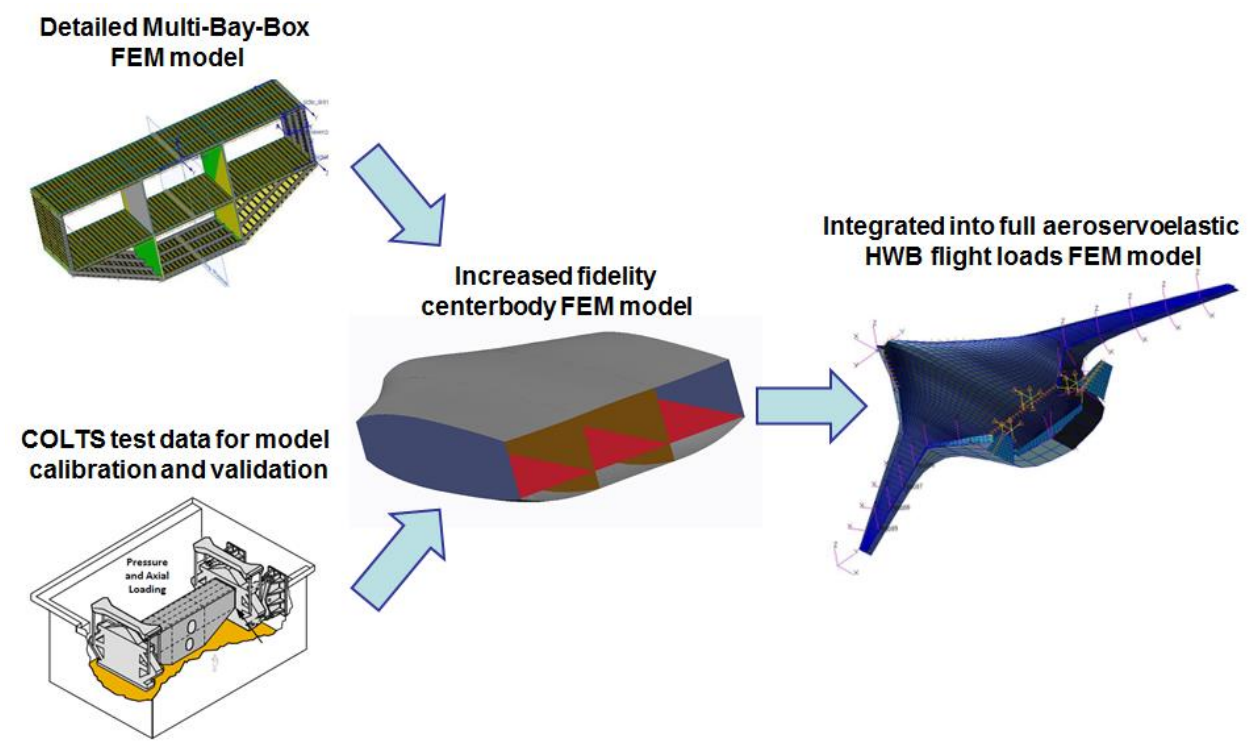

Figure 15: Integration of a detailed centerbody model into the full aeroservoelastic HWB analysis.

In support of ERA's Integrated Technology Demonstrator (ITD) 21A "Damage Arresting Composites Demonstration," the structural model will be extended to include a more detailed representation of the HWB centerbody structure, which will model internal walls, cabin floors, and frames (Figure 15) This will increase the fidelity of structural analyses and weight estimates, while incorporating pre-test predictions and test results from the multi-bay box structural tests in the NASA Langley Combined Loads Test System (COLTS) facility scheduled for $2015 .{ }^{28,29}$

\section{Conclusions}

This paper presents the HCDstruct software as a fast and flexible tool to quickly generate a Nastran ${ }^{\circledR}$ finite element model for structural analysis, optimization, and weight calculation of HWB designs. The tool is highly scalable and can be used to analyze any HWB structure based on a VSP model of the air vehicle and a set of predefined structural parameters. Since the FEM model is based on a direct structural analysis rather than regression or approximation methods, the weight results are suitable for scaling studies or higher-risk alternative configurations. The high degree of scalability allows for flexible numbers of elements in the chordwise, spanwise, and thickness directions, resulting in variable model sizes, degrees of freedom, design variables, and design constraints, rendering the tool suitable for exploring design sensitivities and convergence studies.

The HCDstruct tool has been validated using available data from preliminary design efforts by The Boeing Company, FLOPS weights results, aerodynamic data from X-48B wind tunnel testing, Vorview vortex lattice analyses, and non-proprietary Boeing OREIO open rotor HWB data. Results from the FEM optimization for the OREIO agree well with results from Boeing and FLOPS analyses.

Recent updates to HCDstruct are geared towards expanding the number of available load cases as well as increasing modeling flexibility and fidelity. HCDstruct has been used for structural sizing and optimization, structural weight predictions, aeroelastic analyses, and flight controls and actuation power optimization. Ongoing efforts will further increase its applicability to these problems by developing a full wing tip-to-wing tip analysis capability and a detailed centerbody representation for truly asymmetric maneuver loads and aeroservoelastic analyses.

\section{Acknowledgements}

The development of HCDstruct has been supported by various NASA funds and projects. The structural analysis part of the work has been supported by NASA's Environmentally Responsible Aviation (ERA) project. The flight controls work was supported by NASA's Aeronautics Research and Mission Directorate (ARMD) through the ARMD 
Seedling Fund project "Artificial Intelligence Based Control Power Optimization on Tailless Aircraft." Ongoing improvements to the tool are supported by NASA Langley's Aeronautics Research Directorate (ARD) through their Bid \& Proposal Fund, as well as by the ARMD Transformational Tools \& Technologies $\left(\mathrm{T}^{3}\right)$ project under its Revolutionary Tools \& Methods sub-project.

The author would also like to thank the following contributors to this paper:

- Rupanshi Chhabra, Sameer Mulani, Rakesh Kapania, and Joseph Schetz from Virginia Tech for providing results from their neurocomputing process (Figure 12),

- Nikhil Nigam from IAI for providing details on their coupled OpenVSP/HCDstruct parametric geometry weight estimation process (Figure 13),

- and Jesse Quinlan from the Aeronautics Systems Analysis Branch at NASA Langley for his support in developing the full wing tip-to-wing tip modeling capability in HCDstruct (Figure 14).

\section{References}

1 Liebeck, R.H., "Design of the BWB Subsonic Transport", AIAA-2002-0002, 40 ${ }^{\text {th }}$ AIAA Aerospace Sciences Meeting and Exhibit, January 14-17, 2002, Reno, NV.

2 Risch, T., Cosentino, G., Regan, C.D., Kisska, M., and Princen, N., “X-48B Flight-Test Progress Overview,” AIAA-20090934, $47^{\text {th }}$ AIAA Aerospace Sciences Meeting and Exhibit, January 5-8, 2009, Orlando, Florida.

3 McCullers, L. A., "FLOPS Flight Optimization System,” FLOPS Users Manual, updated Dec. 2009.

4 Gern, F.H., "Improved Aerodynamic Analysis for Hybrid Wing Body Conceptual Design Optimization," AIAA-2012-0249, $50^{\text {th }}$ AIAA Aerospace Sciences Meeting and Exhibit, January 9-12, 2012, Nashville, Tennessee.

5 Gern, F.H., "Finite Element Based HWB Centerbody Structural Optimization and Weight Prediction," AIAA-2012-1606, 53 ${ }^{\text {rd }}$ AIAA/ASME/ASCE/AHS/ASC Structures, Structural Dynamics and Materials Conference, April 23-26, 2012, Honolulu, Hawaii.

6 Nickol, C.L. and McCullers, L.A., "Hybrid Wing Body Configuration System Studies," AIAA-2009-0931, 47th AIAA Aerospace Sciences Meeting and Exhibit, January 5-8, 2009, Orlando, Florida.

7 Bradley, K.R., "A Sizing Methodology for the Conceptual Design of Blended-Wing-Body Transports," NASA/CR-2004213016, NASA Langley Research Center, Hampton, Virginia, September 2004.

8 Li, V. and Velicki, A., “Advanced PRSEUS Structural Concept Design and Optimization," AIAA-2008-5840, 12th AIAA/ISSMO Multidisciplinary Analysis and Optimization Conference, 10-12 September 2008, Victoria, British Columbia, Canada.

9 Hahn, A., "Vehicle Sketch Pad: A Parametric Geometry Modeler for Conceptual Aircraft Design," 48th AIAA Aerospace Sciences Meeting and Exhibit, January 4-7, 2010, Orlando, Florida.

10 MSC Nastran 2008, Quick Reference Guide, MSC Software Corporation, 2 MacArthur Place, Santa Ana, CA 92707, USA, 2008, p. 2077.

11 Pitera, D.M., DeHaan, M., Brown, D., Kawai, R.T., Hollowell, S., Camacho, P., Bruns, D., and Rawden, B.K., Blended Wing Body Concept Development with Open Rotor Engine Integration, NASA/CR-2011-217303, The Boeing Company, Huntington Beach, California, November 2011.

12 Czech, M.J. and Thomas, R.H., "Experimental Studies of Open Rotor Installation Effects," AIAA-2011-4047, $3^{\text {rd }}$ AIAA Atmospheric Space Environments Conference, June 27 - 30, 2011, Honolulu, Hawaii.

13 Collier, F. S., Thomas, R, Nickol, C. A., Lee, Chi-Ming, Tong, M. "Environmentally Responsible Aviation - Real Solutions for Environmental Challenges Facing Aviation, $27^{\text {th }}$ International Congress of the Aeronautical Sciences, Paper No. 802, Nice, France, September, 19-24, 2010.

14 Convention on International Civil Aviation, Aerodromes, Annex 14, Volume I, Aerodrome Design and Operations, International Civil Aviation Organization (ICAO) Sixth Edition, July 2013.

15 LeDoux, S.T., Herling, W.W., Fatta, G.J., and Ratcliff, R.R., "MDOPT - A Multidisciplinary Design Optimization System Using Higher Order Analysis Codes," AIAA 2004-4567, $10^{\text {th }}$ AIAA/ISSMO Multidisciplinary Analysis and Optimization Conference, August 30 - September 1, 2004, Albany, New York.

16 Johnson, F.T., Tinoco, E.N., and Yu, N.J., "Thirty Years of Development and Application of CFD at Boeing Commercial Airplanes, Seattle," AIAA-2003-3439, 16 ${ }^{\text {th }}$ AIAA Computational Fluid Dynamics Conference, June 23-26, 2003, Orlando, Florida.

17 Gern, F.H., "Conceptual Design and Structural Analysis of an Open Rotor Hybrid Wing Body Aircraft," AIAA Paper 2013$1688,54^{\text {th }}$ AIAA/ASME/ASCE/AHS/ASC Structures, Structural Dynamics and Materials Conference, April 8-11, 2013, Boston, Massachusetts. 
18 Velicki, A., Thrash, P., and Jegley, D., “Airframe Development for the Hybrid Wing Body Aircraft," AIAA-2009-932, 47 AIAA Aerospace Sciences Meeting Including The New Horizons Forum and Aerospace Exposition, January 5-8, 2009, Orlando, Florida.

19 Yovanof, N.P., Velicki, A., and Li, V., “Advanced Structural Stability Analysis of a Noncircular, BWB-Shaped Vehicle," AIAA-2009-2452, 50 ${ }^{\text {th }}$ AIAA/ASME/ASCE/AHS/ASC Structures, Structural Dynamics, and Materials Conference, May 4-7, 2009, Palm Springs, California.

20 MSC Nastran 2005 r3, Design Sensitivity and Optimization, User's Guide, MSC Software Corporation, 2 MacArthur Place, Santa Ana, CA 92707, USA, 2005.

21 Federal Aviation Regulations Part 25 - Airworthiness Standards: Transport Category Aircraft, US Department of Transportation, 1974.

22 Velicki, A., Damage Arresting Composites for Shaped Vehicles, NASA/CR-2009-215932, The Boeing Company, Huntington Beach, California, NASA Langley Research Center, Hampton, Virginia, 23681-2199, September 2009.

23 Gern, F.H., Vicroy, D.D., Kapania, R.K., Schetz, J.A., Mulani, S.B., Chhabra, R., Brown, D., and Princen, N.H., "Artificial Intelligence Based Control Power Optimization on Tailless Aircraft," ARMD Seedling Fund Phase I Final Report, NASA Technical Memorandum, NASA/TM-2014-218671, December, 2014.

24 Rodden, W.P. and Johnson, E.H. (Editors), MSC.Nastran Version 68, Aeroelastic Analysis User's Guide, MSC Software.

25 Chhabra, R., Mulani, S.B., Kapania, R.K., and Schetz, J.A., "Control Power Optimization using Artificial Intelligence for Hybrid Wing Body Aircraft," Aviation 2015, June 22-26, 2015, Dallas, Texas.

26 Nigam, N., Ayyalasomayajula, S., Qi, X., Chen, P., Alonso, J.J., and Variyar, A., "High-Fidelity Weight Estimation for Multidisciplinary Conceptual Aircraft Design," Aviation 2015, June 22-26, 2015, Dallas, Texas.

27 Kirby M.R. and Mavris, D.N., "The Environmental Design Space," $26^{\text {th }}$ International Congress of the Aeronautical Sciences, Paper No. 473, Anchorage, Alaska, September 14-19, 2008.

28 Jegley, D. and Velicki, A., "Status of Advanced Stitched Unitized Composite Aircraft Structures," AIAA-2013-0410, 51" AIAA Aerospace Sciences Meeting including the New Horizons Forum and Aerospace Exposition, January 7-10, 2013, Grapevine, Texas.

29 Velicki, A. and Jegley, D., "PRSEUS Structural Concept Development," AIAA-2014-0259, 52 ${ }^{\text {nd }}$ Aerospace Sciences Meeting, AIAA SciTech, 13-17 January 2014, National Harbor, Maryland. 